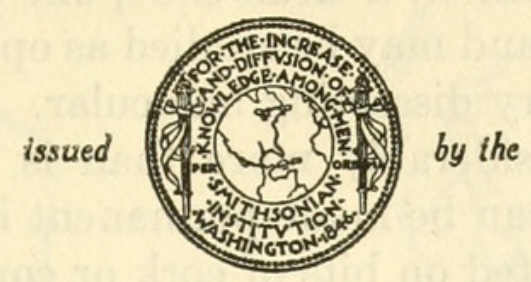

SMITHSONIAN INSTITUTION

U. S. NATIONAL MUSEUM

\title{
A NEW SPECIES OF PHYLLOPOD CRUSTACEAN FROM THE SOUTHWESTERN SHORT-GRASS PRAIRIES
}

\section{By J. G. Mackin}

AfTER several years of collecting streptocephalids in the Southern Plains regions of the United States, it has become apparent that some of the specimens do not conform with descriptions of Streptocephalus texanus Packard, to which species I have previously assigned all streptocephalids not having the peculiar spinous furcae of $S$. seali. I have in the past considered $S$. texanus rather variable. The study of a large number of specimens showed clearly that an undescribed species was present and that characters of all streptocephalids of our Plains region are quite constant. I am much indebted to my wife, Dorothy Louise Mackin, for the preparation of several hundreds of slides making possible the clear distinctions. I accordingly name the new species in her honor.

Technique.-Two techniques were followed in these studies. The first consists of staining specimens with acid fuchsin and dissecting and mounting as usual in Canada balsam. The other method is one worked out to aid in the study of comparatively large parts and organs of these phyllopods, such as the clasping antennae. Specimens are stained with acid fuchsin, with a few drops of hydrochloric acid added as usual, and then are run through the alcohols to benzene. A little Canada balsam is added to the benzene, and the specimens are then dissected. In dissecting for the clasping antennae, the head is cut off and then split along the sagittal plane, so that the two claspers are separated. The benzene is then allowed to evaporate slowly. If done gradually enough, distortion is eliminated. The balsam gives 
the specimens a smooth, glossy coat. Both claspers are then stuck with glue or thick balsam on a clean slide, one showing internal view and the other external, and may be studied as opaque objects by direct lighting with an ordinary dissecting binocular. The detail to be seen by this method is considerably more than is possible with cleared mounts. The mounts can be made permanent if protected from dust by a cover glass supported on bits of cork or cork rings.

\title{
Genus STREPTOCEPHALUS Baird
}

\section{STREPTOCEPHALUS DOROTHAE, new specieq}

\author{
Figures 4, B; 5, B
}

Description. ${ }^{1-}$ The clasping antennae present definite characters that may be noted at a glance. The appendage is rather slender, and the first two segments are much wrinkled on the surface. The spinous processes in a row on the internal surface of the second segment are long and numerous, but this is not a reliable character. The third segment, or scissors, affords the best identification marks. The internal shorter branch bears two processes at the base on the anterior surface (fig. 4, B, at $f$ ). The shorter proximal one of these curves sharply inward (in fig. 4, B, toward the observer). The distal process is long and slender and curves around the body of the appendage and thus is partly hidden from internal view. (Compare these processes with the homologous struetures in $S$. texanus shown in fig. 4 , A, at c.) Toward the distal end of the inner branch of the scissors, shown at $d$ in fig. $4, \mathrm{~B}$, is a swollen area, the anterior surface of which is thinwalled and apt to be wrinkled. There is no process on the posterior side as in S. texanus. (Compare with fig. 4, A, at a of $S$. texanus.) One character of the external longer branch of the scissors is distinctive: The peculiar shape of the end of the posterior spur, which projects from near the base proximal to the "elbow" (fig. 4, B, at $e$ ). I have likened this shape of the end of the spur to a tiny foot, seen from side view, the rounded bump on the lower side being the "heel" and the point the "toe." (Compare the spur with that of $S$. texanus, fig. 4, A, at $b$, which is in the form of a smooth-pointed blade.) After comparing hundreds of specimens of $S$. dorothae and texanus, I am convinced that these characters of the claspers are constant. One character of the swimming appendages may be of value: In $S$. dorothae the bract is serrate over the entire outer margin. In $S$. texanus there are only a few small spines on this margin at the proximal end, and the remainder is smooth.

\footnotetext{
${ }^{1}$ In this diagnosis I have eliminated characters of generic and family rank. For instance, if there is nothing distinctive about the first antennae in peculiarities of shape, segmentation, etc., I see no necessity for noting the presence of the appendage, since it is present in all the Streptocephalidae. Thus I have omitted discussion of many characters usually mentioned in descriptions of streptocephalids, hoping to focus attention on those of most value. I do not find streptocephalids difficult to identify, and I am convinced that diffculties experienced by others are due to confusion of species by Packard and other earlier writers.
} 

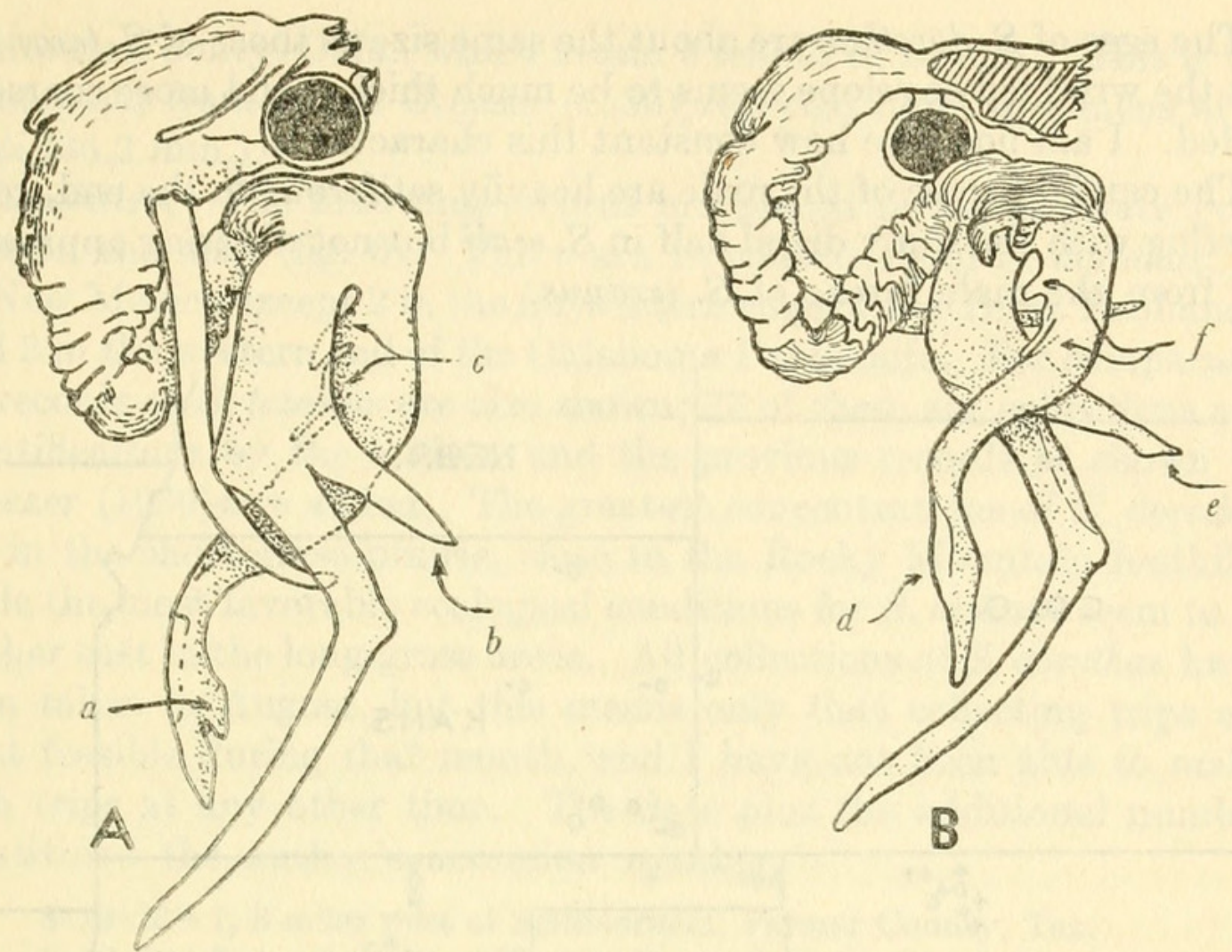

Figure 4.-A, Streptocephalus texanus: Lateral view of second antennae ( $a$, distal end of inner branch of scissors, showing posterior process; $b$, spur projecting from outer branch near the base proximal to the elbow, showing characteristic apex; $c$, the two processes at the base of the anterior surface of the internal shorter branch); B, S. dorothae: Median view of male second antennae ( $d$, distal end of inner branch of scissors, showing swollen area; $e$, spur projecting from outer branch near the base proximal to the elbow, showing characteristic apex; $f$, the two processes at the base of the anterior surface of the internal shorter branch).
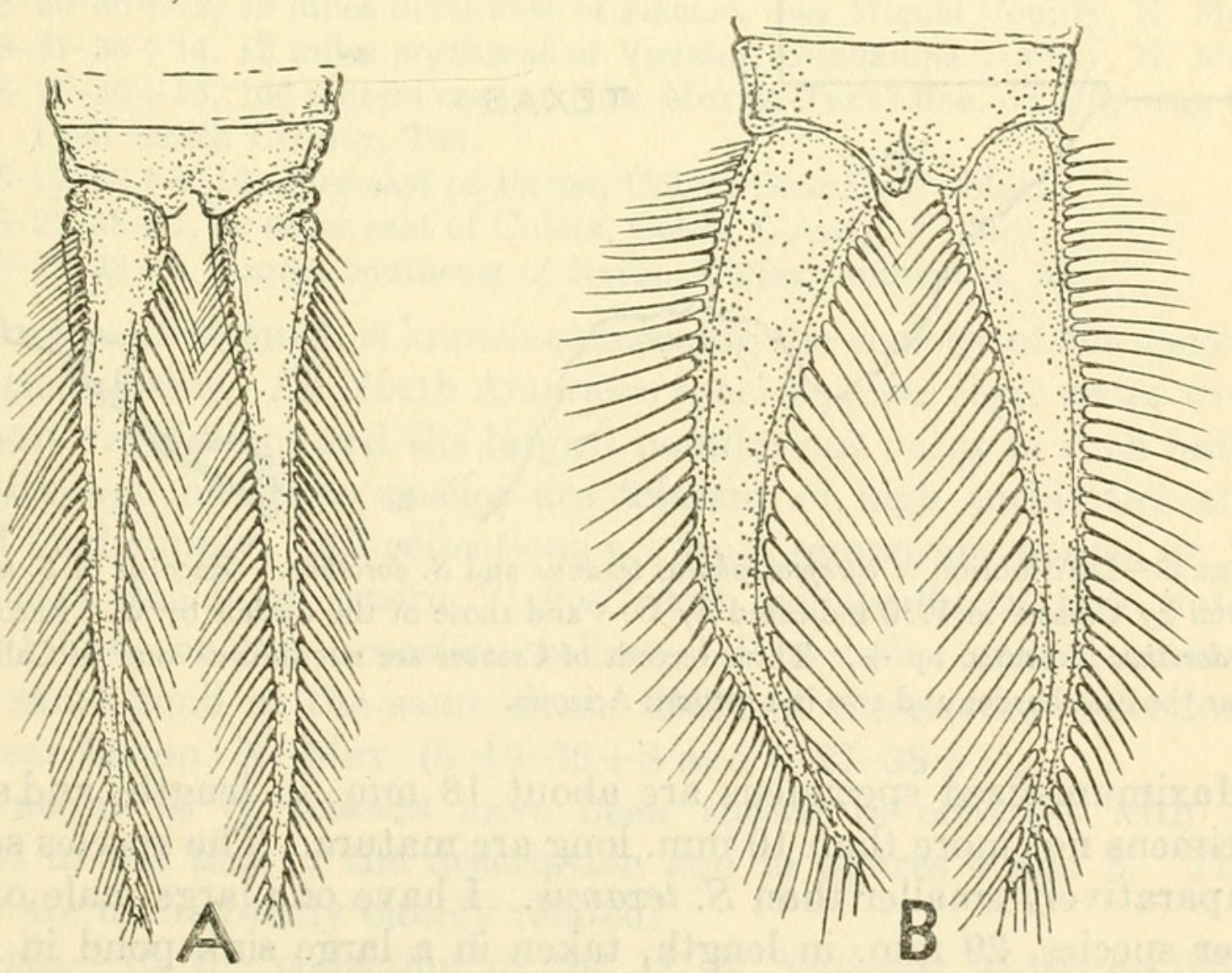

Figure 5.-A, Streptocephalus texanus: Caudal furcae of male; B, S. dorothae: Caudal furcae of male. 
The eggs of $S$. dorothae are about the same size as those of $S$. texanus, but the wrinkled envelope seems to be much thicker and more coarsely folded. I am not sure how constant this character is.

The caudal furcae of the male are heavily setiferous to the end, contrasting with the spiny distal half in $S$. seali but not differing appreciably from the male furcae of $S$. texanus.

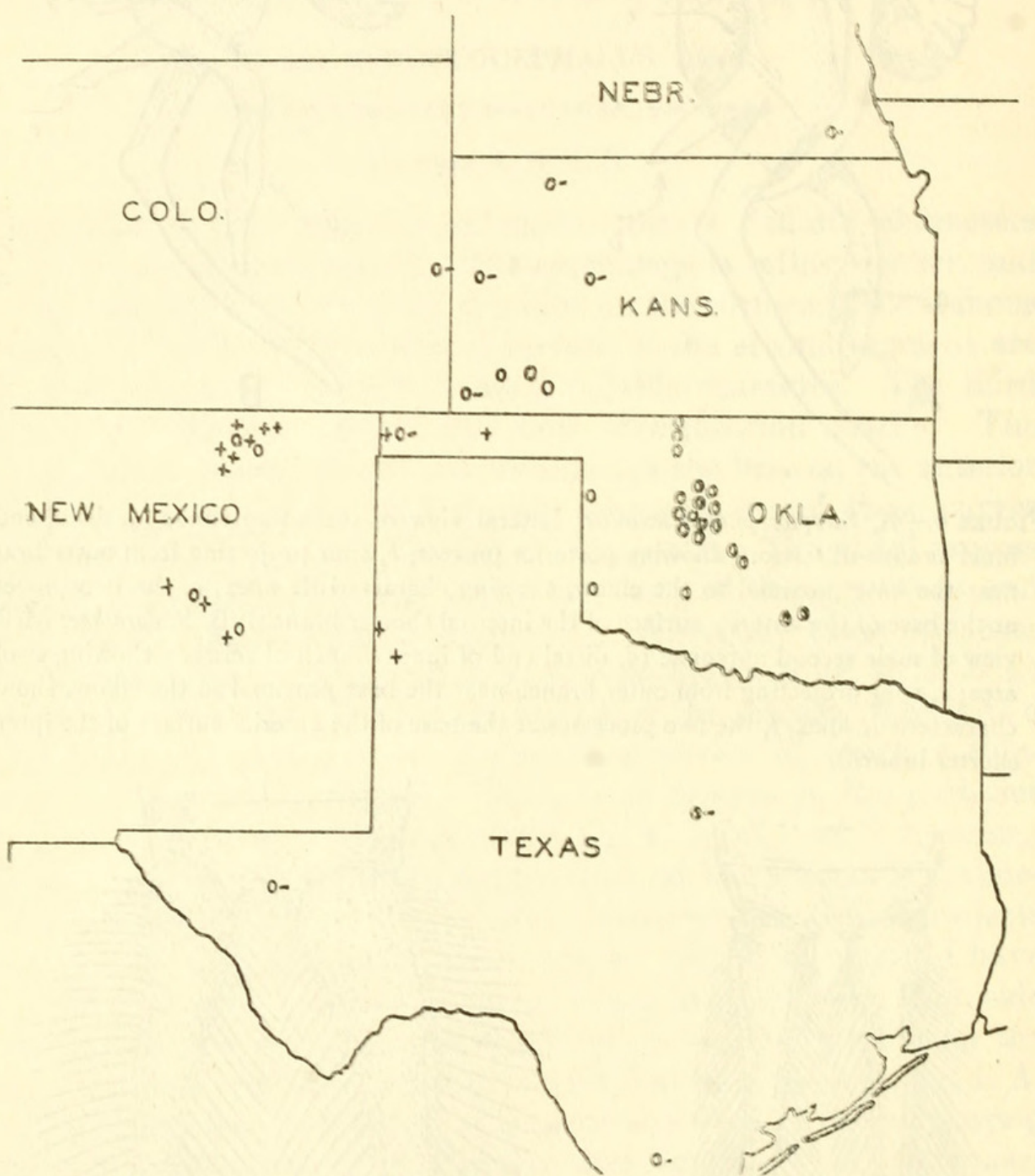

Figure 6.-Distribution of Streptocephalus texanus and S. dorothae. Records of S. texanus given by Creaser in 1930 indicated by $\mathrm{O}-$ and those of the author by O. Records of $S$. dorothae indicated by + . Three records of Creaser are not shown-one in California near the east border and two in southern Arizona.

Maximum-sized specimens are about $18 \mathrm{~mm}$. in length, and some specimens not more than $10 \mathrm{~mm}$. long are mature. The species seems comparatively smaller than $S$. texanus. I have one large male of the latter species, $29 \mathrm{~mm}$. in length, taken in a large sink pond in New Mexico, south of Santa $\mathrm{Fe}$, and a number of specimens from a pond in 
Pontotoc County, Okla., which attain a length of $23 \mathrm{~mm}$. This is the same pond from which Creaser (1930) reported large specimens of $S$. seali $(36.2 \mathrm{~mm}$.).

Localities.-The following records are placed in approximate position on the map (fig. 6). There are 14 collections of $S$. dorothae, all in New Mexico except 2 in the far western edge of the Texas Panhandle and 2 in the western end of the Oklahoma Panhandle. For comparison all records of $S$. texanus are also shown; 27 of these are collections and identifications by the author, and the previous records as shown by Creaser (1930) are added. The greatest concentrations of $S$. dorothae are in the short-grass prairie, close to the Rocky Mountain foothills, while the most favorable ecological conditions for S. texanus seem to be farther east in the long-grass areas. All collections of S. dorothae have been taken in August, but this means only that collecting trips are most feasible during that month, and I have not been able to make such trips at any other time. The date plus the additional number constitutes the author's accession number.

8-12-28+1, 8 miles west of Summerfield, Parmer County, Tex.

8-18-36+3, 1 mile west of Turpin, Texas County, Okla.

8-18-36+4, 12 miles east of Boise City, Cimarron County, Okla.

8-19-36+6, 2 miles west of Capulin, Union County, N. Mex.

$8-19-36+7,10$ miles west of Capulin, Colfax County, N. Mex.

$8-19-36+8,10$ miles southeast of Raton, Colfax County, N. Mex.

8-19-36+10, 3 miles south of Raton, Colfax County, N. Mex.

8-20-36+11, 20 miles south of Santa Fe, Santa Fe County, N. Mex. (type locality).

8-20-36+12, 35 miles northwest of Encino, San Miguel County, N. Mex.

8-21-36+14, 12 miles northeast of Vaughn, Guadalupe County, N. Mex.

8-21-36+15, 100 meters east of New Mexico-Texas line, on Highway 66,

Deaf Smith County, Tex.

$8-27-38+3,10$ miles east of Raton, Colfax County, N. Mex.

$8-27-38+1,20$ miles east of Colfax, Colfax County, N. Mex.

$8-27-38+2,5$ miles southeast of Raton, Colfax County, N. Mex.

Remarks.- Not much is known concerning the ecology of the species of Streptocephalus. All North American species prefer clear water with abundant vegetation, and the largest populations occur in such habitats, although all three species are tolerant of high turbidities and limited food supply. All collections are from temporary ponds, or, in some cases, the large prairie "lakes" with widely fluctuating water level. I have on two occasions collected $S$. dorothae and $S$. texanus in the same pond at the same time. Both of these were collections from near Raton, N. Mex. (8-19-36+8 and 8-27-38+3).

Characters of $S$. texanus have been shown in contrast with $S$. dorothae in the text of the description and in figures 4 and 5 . The species are undoubtedly closely related.

Cotypes.-In the collection of the U. S. National Museum (No. 79019) and in the collection of the author. 


\section{PACKARD'S DESCRIPTIONS OF STREPTOCEPHALUS TEXANUS}

From a thorough study of the original and subsequent descriptions of $S$. texanus it becomes clear that Packard confused specimens of $S$. seali with his new species. The original description (1871) is vague, but the fact that he compared it with $S$. similis Baird, 1854, and stated its close kinship to this species shows that he must have had some specimens of $S$. seali. This is borne out by the fact that the figure 13 published with his short notice of $S$. texanus in 1874 is certainly a figure of $S$. seali. It is a rather crude drawing, but characters of the furcae and clasping antennae indicate $S$. seali rather clearly. In 1877 Packard described S. watsoni, using specimens from Ellis, Kans. (U. S. N. M. No. 58808). Subsequently he declared this species a synonym of $S$. texanus (1883) and repeated the description as a part of a redescription of $S$. texanus. Since this last description seems to be free from confusion with $S$. seali and is accompanied by good figures, our conception of $S$. texanus should be based on this one, and the original used for the sake of establishing priority alone. Incidentally, the cotypes of $S$. watsoni, in the absence of types of $S$. texanus, become the real basis for the latter species. Through the courtesy of the U. S. National Museum I have examined these specimens and thereby verified my own identifications.

\section{KEY TO NORTH AMERICAN SPECIES OF STRETOCEPHALUS}

(Modified from Creaser, 1930, to include S. dorothae)

1. Nale caudal furcae with setae along basal portion and heavy, curved spines distally

Male caudal furcae setiferous along entire margin _.................... 3

2. Inner shorter branch of male clasping antennae with 2 processes on anterior

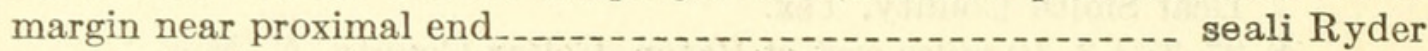

Inner shorter branch of male clasping antennae with 3 processes on anterior margin near proximal end._...... similis Baird

3. Inner branch of male clasping antennae with a process on posterolateral margin near distal end; posterior spur of the longer outer branch blade-shaped.

texanus Packard

Inner branch of male clasping antennae without a process near distal end; posterior spur of the longer outer branch shaped like a miniature foot at the end.................. dorothae, new species 


\section{LITERATURE CITED}

Creaser, Edwin Phillip.

1930. The North American phyllopods of the genus Streptocephalus. Occ. Pap. Mus. Zool. Univ. Michigan, No. 217, 10 pp.

Packard, Alpheus Spring, Jr.

1871. Preliminary notice of North American Phyllopoda. Amer. Journ. Sci. and Arts, ser. 3, vol. 2, pp. 108-113.

1874. Synopsis of the fresh-water phyllopod Crustacea of North America. Ann. Rep. U. S. Geol. Geogr. Surv. Terr. for 1873, pp. 613-622.

1877. Descriptions of new phyllopod Crustacea from the West. U.S. Geol. Geogr. Surv. Terr. Bull. 3, pp. 171-185.

1883. A monograph of the phyllopod Crustacea of North America, with remarks on the order Phyllocarida. Ann. Rep. U. S. Geol. Geogr. Surv. Terr. for 1878, pt. 1, pp. 295-592. 


\section{$2 \mathrm{BHL}$ Biodiversity Heritage Library}

Mackin, J G. 1942. "A new species of phyllopod crustacean from the southwestern short-grass prairies." Proceedings of the United States National Museum 92(3136), 33-39. https://doi.org/10.5479/si.00963801.92-3136.33.

View This Item Online: https://www.biodiversitylibrary.org/item/53694

DOI: https://doi.org/10.5479/si.00963801.92-3136.33

Permalink: https://www.biodiversitylibrary.org/partpdf/52737.

\section{Holding Institution}

Smithsonian Libraries

\section{Sponsored by}

Smithsonian

\section{Copyright \& Reuse}

Copyright Status: Public domain. The BHL considers that this work is no longer under copyright protection.

This document was created from content at the Biodiversity Heritage Library, the world's largest open access digital library for biodiversity literature and archives. Visit BHL at https://www.biodiversitylibrary.org. 